\title{
A further experimental study of the antisilicotic effect of glutamate
}

\author{
K I MOROSOVA, B A KATSNELSON, YU S ROTENBERG, AND G V BELOBRAGINA* \\ From the Institute of Industrial Hygiene and Occupational Diseases, Sverdlovsk, USSR
}

\begin{abstract}
Two groups of rats were exposed to quartz dust for six months and in addition one group was given drinking water containing $1.5 \%$ sodium glutamate while the second received only water. In the rats receiving glutamate we observed $(a)$ evidence for a considerably reduced cytotoxic effect of the quartz on cells obtained by bronchopulmonary lavage, (b) a reduction in dust retention in the lungs, especially in the tracheobronchial lymph nodes, (c) a considerable reduction in the weight gain in the lungs and in their hydroxyproline and lipid contents, and $(d)$ the inhibition of the formation of silicotic nodules. Polarographic studies of the oxygen consumption of peritoneal macrophages from rats receiving glutamate showed that glutamate prevents the adverse effects of quartz on mitochondrial oxidative processes.
\end{abstract}

It was found earlier ${ }^{2}$ that the long term administration of a $1.5 \%$ glutamate solution in drinking water partly inhibits the development of lung fibrosis in rats after intratracheal injections of quartz and asbestos dust. A subsequent series of experiments in vitro and in vivo proved that this effect is, most probably, due to a considerable increase in the resistance of the macrophage to the cytotoxic action of the dust. ${ }^{23}$ Taking into consideration the role of damage to this cell not only in inducing silicotic fibrogensis but also in pulmonary dust retention, we suggested that the protective effect of glutamate might be even more pronounced in the long term inhalation of dust by rats. ${ }^{2}$ This prognosis was fully confirmed by a new experiment, the results of which are discussed in this paper.

Simultaneously we have continued our studies directed at further clarification of the role of the normalising influence of glutamate on the. energy metabolism of the macrophage under the cytotoxic action of silica which may be the leading cause of the above mentioned cytoprotective effect. Data on the correspondence between such an effect and the beneficial influence of glutamate on the energy potential of the system of adenosine nucleotides of the cell $^{24}$ were a precondition to these studies.

Received 4 July 1983

Accepted 26 September 1983

*Dr G V Belobragina died on 6 September 1982.

\section{Material and methods}

Male rats with an initial body weight of $160-200 \mathrm{~g}$ were exposed to the inhalation (five times a week, five hours a day) of dust formed by blowing air through a rotating drum containing pulverised quartz rock which was $92-94 \%$ alpha-quartz. The mean concentration of total airborne dust in the chamber in which the animals were placed during the six month period of the experiment was $71 \cdot 3 \pm$ $1.9 \mathrm{mg} / \mathrm{m}^{3}$. Outside the dust chamber some of the rats were given water to drink and others were given a $1.5 \%$ solution of glutamic acid neutralised by sodium bicarbonate. Two similar groups of animals were not exposed to quartz. Some 15-20 rats of each of the four groups were killed by the end of the third month (the first stage), and the same number by the end of the sixth month (the second stage) of the experiment. Six of this number were used for the preparation of lung and tracheobronchial lymph nodes sections with subsequent histological study under light microscope, and in other rats the weight of these organs was measured, as well as their dust, ${ }^{5}$ total hydroxyproline ${ }^{6}{ }^{6}$ and total lipid ${ }^{7}$ content.

When the lungs were removed, they were first subjected to a single washing out with normal saline through the trachea. The total number of cells in an aliquot sample of lavage was counted, and the remaining volume of lavage was centrifuged. Smears of the sediment were stained to determine the ratio 
-Table 1 Main cytological characteristics of bronchopulmonary lavage of experimental and control rats $\left(\bar{X} \pm S_{\bar{\lambda}}\right)$

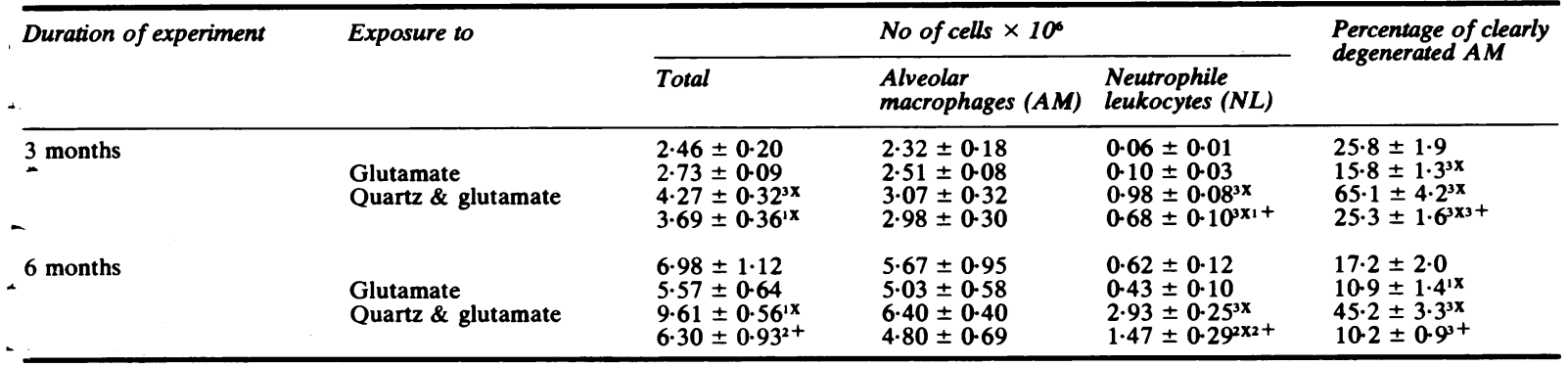

Indices 1, 2, and 3 show values that differ with statistical significance (with $\mathrm{p}$, correspondingly, $<0.05,<0 \cdot 01$, and $<0.001$ ) from the intact control gtoup (index $x$ ), and for the group "quartz and glutamate" - also from group "quartz" (index + ).

- of cells of different types, the number of observed phagocytised dust particles, and the number of cells which could be reliably identified as macrophages but which possessed evident morphological and tinctorial signs of degeneration.

In a separate series of experiments with rats which drank the glutamate solution (corresponding controls drinking water) for two or four months we obtained peritoneal macrophages using the same techniques as described earlier in this journal. ${ }^{2}$ After centrifuging and washing with normal saline the cell sediment was resuspended with Hanks' solution to give a final concentration of $3.5 \times 10^{6}$ cells per ml after which $2 \mathrm{mg} D_{12}$ quartz suspended in $1 \mathrm{ml}$ Hanks' solution were added to one portion of cell suspension of $1 \mathrm{ml}$ volume, and $1 \mathrm{ml}$ of the same solution without quartz was added to a similar portion. After incubation for one hour at $37^{\circ} \mathrm{C}$ the oxygen consumption of the cells was estimated polarographically by means of a Clark type oxygen electrode. The measurement was first conducted without introducing any exogenic substrates into the system (endogenous respiration) and then in the presence of sodium succinate $5 \times 10^{-3} \mathrm{M}, 2,4$ - dinitrophenol $1 \times 10^{-5} \mathrm{M}$, and sodium cyanide $2 \times$ $10^{-5} \mathrm{M}$. Special samples of the same cell suspensions were used to determine the critical oxygen concentration limiting endogenous respiration.

An additional experiment was performed to test the influence of the preincubation of peritoneal macrophages (from rats not subjected to any influence) with sodium glutamate or with sodium succinate in concentrations of $3.4 \times 10^{-4} \mathrm{M}$ on the degree of inhibition of TTC-reductase activity caused by the incubation with $\mathrm{DQ}_{12}$ quartz in $2 \mathrm{mg}$ doze per $3.5 \times 10^{-6}$ cells. Their technique has been described elsewhere. ${ }^{2}$

\section{Results}

Granulomas possessing the characteristic features of "typical" silicotic nodules, although with a moderately developed collagen fibrosis, were found in large numbers after only six months exposure to quartz dust, and as a rule only in the rats that drank water. At the end of the experiment as well as after a three month period, the animals receiving glutamate showed a preponderance of cellular nodules of

Table 2 Some quantitative indices of the state of lungs and tracheobronchial lymph nodes of experimental and control rats $\left(\bar{X} \pm S_{\bar{x}}\right)$

\begin{tabular}{|c|c|c|c|c|c|c|c|c|}
\hline \multirow{2}{*}{$\begin{array}{l}\text { Duration of } \\
\text { experiment }\end{array}$} & \multirow[t]{2}{*}{ Exposure to } & \multicolumn{4}{|l|}{ Lungs } & \multicolumn{3}{|l|}{ Lymph nodes } \\
\hline & & $\begin{array}{l}\text { Dry weight } \\
\text { (mg) }\end{array}$ & $\begin{array}{l}\text { Dust content } \\
\text { (mg) }\end{array}$ & $\begin{array}{l}\text { Hydroxyproline } \\
\text { content (mg) }\end{array}$ & $\begin{array}{l}\text { Lipid content } \\
\text { (mg) }\end{array}$ & $\begin{array}{l}\text { Wet weight } \\
\text { (mg) }\end{array}$ & $\begin{array}{l}\text { Dust } \\
\text { content (mg) }\end{array}$ & $\begin{array}{l}\text { Hydroxy- } \\
\text { proline } \\
\text { content }(\mu g)\end{array}$ \\
\hline 3 months & $\begin{array}{l}\text { Glutamate } \\
\text { Quartz } \\
\text { Quartz \& } \\
\text { glutamate }\end{array}$ & $\begin{array}{l}378 \cdot 8 \pm 19 \cdot 6 \\
328 \cdot 2 \pm 10 \cdot 71 x \\
391 \cdot 6 \pm 14 \cdot 7 \\
380 \cdot 9 \pm 6 \cdot 0\end{array}$ & $\begin{array}{l}2 \cdot 9 \pm 0.6 \\
1 \cdot 0 \pm 0.31 x \\
7 \cdot 0 \pm 0.9 \\
5 \cdot 6 \pm 0.4\end{array}$ & $\begin{array}{l}4617 \pm 234 \\
4096 \pm 131 \\
4642 \pm 166 \\
4438 \pm 105\end{array}$ & $\begin{array}{l}43 \cdot 5 \pm 2 \cdot 8 \\
34 \cdot 8 \pm 1 \cdot 7^{1 x} \\
48 \cdot 9 \pm 3 \cdot 5 \\
45 \cdot 2 \pm 1.4\end{array}$ & $\begin{aligned} 55 \cdot 8 & \pm 7 \cdot 0 \\
40 \cdot 4 & \pm 4 \cdot 4 \\
112 \cdot 4 & \pm 10 \cdot 1^{3 x} \\
93 \cdot 6 & \pm 8 \cdot 5\end{aligned}$ & $\begin{array}{l}0.23 \\
0.05 \\
1.06 \\
0.14\end{array}$ & $\begin{array}{r}100 \\
56 \\
188 \\
113\end{array}$ \\
\hline $\begin{array}{l}\text { 6-months } \\
\text { - }\end{array}$ & $\begin{array}{l}\text { Glutamate } \\
\text { Quartz } \\
\text { Quartz \& } \\
\text { glutamate }\end{array}$ & $\begin{array}{l}403 \cdot 5 \pm 13 \cdot 4 \\
346 \cdot 0 \pm 11 \cdot 1^{2 \mathrm{x}} \\
635 \cdot 7 \pm 31 \cdot 0^{3 \mathrm{x}} \\
511 \cdot 9 \pm 21 \cdot 1^{1 \times 2}+\end{array}$ & $\begin{aligned} 2 \cdot 3 & \pm 0 \cdot 4 \\
0 \cdot 8 & \pm 0 \cdot 2^{2 x} \\
16 \cdot 0 & \pm 1 \cdot 8^{3 x} \\
5 \cdot 8 & \pm 0 \cdot 5^{2 \times 3}+\end{aligned}$ & $\begin{array}{l}5310 \pm 189 \\
4442 \pm 154^{2 x} \\
7165 \pm 369^{3 x} \\
5307 \pm 315^{3+}\end{array}$ & $\begin{aligned} 55 \cdot 2 & \pm 3 \cdot 6 \\
51 \cdot 8 & \pm 2 \cdot 7 \\
125 \cdot 3 & \pm 10 \cdot 5^{3 \times} \\
85 \cdot 5 & \pm 8 \cdot 7^{2 \times 2+}\end{aligned}$ & $\begin{array}{l}132 \cdot 5 \pm 15 \cdot 3 \\
124 \cdot 6 \pm 12 \cdot 6 \\
315 \cdot 8 \pm 23 \cdot 8^{3 x} \\
193 \cdot 1 \pm 22 \cdot 3^{1 \times 3}+\end{array}$ & $\begin{array}{l}0.24 \\
0.05 \\
2.22 \\
0.51\end{array}$ & $\begin{array}{l}144 \\
\text { No data } \\
448 \\
300\end{array}$ \\
\hline
\end{tabular}

Dust and hydroxyproline content in lymph nodes were determined in pooled tissue samples which preclude the estimation of standard errors of indices. All other indices have the same notation of statistical significance as in table 1 . 


\begin{tabular}{|c|c|c|c|c|c|c|}
\hline \multirow[t]{3}{*}{ NL/AM ratio } & \multicolumn{4}{|c|}{ Indices of phagocytic activity } & \multirow{2}{*}{\multicolumn{2}{|c|}{$\begin{array}{l}\text { Total No of phagocytised } \\
\text { particles } \times 10^{6}\end{array}$}} \\
\hline & \multicolumn{2}{|c|}{ Alveolar macrophages } & \multicolumn{2}{|c|}{ Neutrophile leukocytes } & & \\
\hline & $\boldsymbol{A}$ & $\boldsymbol{B}$ & $A$ & $\boldsymbol{B}$ & $\ln A M$ & In $N L$ \\
\hline $\begin{array}{l}0.03 \pm 0.01 \\
0.04 \pm 0.01 \\
0.34 \pm 0.04^{3 \times} \\
0.22 \pm 0.02^{3 \times 2}+\end{array}$ & $\begin{array}{l}67 \cdot 6 \pm 4 \cdot 1 \\
82 \cdot 4 \pm 2 \cdot 7^{2 x} \\
83 \cdot 4 \pm 2 \cdot 9^{2 x} \\
74 \cdot 7 \pm 2 \cdot 0^{1+}\end{array}$ & $\begin{array}{l}6.16 \pm 0.19 \\
5.98 \pm 0.35 \\
6.80 \pm 0.39 \\
7.90 \pm 0.45\end{array}$ & $\begin{array}{l}36 \cdot 1 \pm 10 \cdot 4 \\
42 \cdot 2 \pm 12 \cdot 3 \\
64 \cdot 8 \pm 4 \cdot 2^{1 x} \\
51 \cdot 5 \pm 4 \cdot 4^{1+}\end{array}$ & $\begin{array}{l}2.28 \pm 0.36 \\
1.38 \pm 0.191 x \\
2 \cdot 16 \pm 0.15 \\
1 \cdot 83 \pm 0.08\end{array}$ & $\begin{array}{r}9603 \\
12367 \\
17412 \\
17587\end{array}$ & $\begin{array}{r}49 \\
58 \\
1372 \\
641\end{array}$ \\
\hline $\begin{array}{l}0.12 \pm 0.02 \\
0.09 \pm 0.02 \\
0.44 \pm 0.02^{3 \times} \\
0.31 \pm 0.04^{3 \times 2}+\end{array}$ & $\begin{array}{l}48 \cdot 1 \pm 3 \cdot 8 \\
54 \cdot 7 \pm 2 \cdot 8 \\
89 \cdot 5 \pm 1 \cdot 5^{3 x} \\
78 \cdot 1 \pm 3 \cdot 2^{3 \times 2}+\end{array}$ & $\begin{array}{l}5 \cdot 03 \pm 0.30 \\
5 \cdot 28 \pm 0 \cdot 19 \\
6.90 \pm 0 \cdot 25^{3 \mathrm{x}} \\
6.90 \pm 0.22^{3 \mathrm{x}}\end{array}$ & $\begin{array}{l}48 \cdot 6 \pm 6 \cdot 4 \\
53 \cdot 5 \pm 8 \cdot 3 \\
82 \cdot 4 \pm 2 \cdot 0^{3 x} \\
64 \cdot 8 \pm 5 \cdot 1^{1+}\end{array}$ & $\begin{array}{l}2.05 \pm 0.16 \\
1.63 \pm 0.16^{1 x} \\
2.68 \pm 0.11^{2 x} \\
2.46 \pm 0.20\end{array}$ & $\begin{array}{l}13712 \\
14536 \\
39522 \\
25860\end{array}$ & $\begin{array}{r}617 \\
314 \\
6469 \\
2341\end{array}$ \\
\hline
\end{tabular}

$A=$ Percentage of cells containing dust particles in the total number of AM and NL.

$B=$ Mean number of visible particles inside one cell containing them.

Table 3 Infuence of glutamate in vivo and quartz dust in vitro on oxygen consumption (in $\mu$-atoms $0 . \mathrm{min}^{-1} 10^{-6}$ cells) by the peritoneal macrophages of rats

\begin{tabular}{|c|c|c|c|c|c|}
\hline \multirow[t]{2}{*}{ Marcophages } & \multirow{2}{*}{$\begin{array}{l}\text { Duration of } \\
\text { experiment }\end{array}$} & \multirow{2}{*}{$\begin{array}{l}\text { Rate of endogenous } \\
\text { breathing }\end{array}$} & \multicolumn{3}{|c|}{ Breathing rate in the presence of } \\
\hline & & & Succinate & 2, 4-Dinitrophenol & Cyanide \\
\hline $\begin{array}{l}\text { From control rats; incubation } \\
\text { without quartz } \\
\text { From control rats; incubation } \\
\text { with quartz } \\
\text { From rats receiving glutamate; } \\
\text { incubation without quartz } \\
\text { From rats receiving glutamate; } \\
\text { incubation with quartz }\end{array}$ & $\begin{array}{l}2 \text { months } \\
4 \text { months } \\
2 \text { months } \\
4 \text { months } \\
2 \text { months } \\
4 \text { months } \\
2 \text { months } \\
4 \text { months }\end{array}$ & $\begin{array}{l}0.266 \pm 0.036 \\
0.194 \pm 0.037 \\
0.196 \pm 0.012^{1+} \\
0.090 \pm 0.017^{1+} \\
0.282 \pm 0.037 \\
0.193 \pm 0.032 \\
0.220 \pm 0.021 \\
0.128 \pm 0.027\end{array}$ & $\begin{array}{l}0.441 \pm 0.035^{1 x} \\
0.318 \pm 0.062 \\
0.334 \pm 0.034^{1 x} \\
0.263 \pm 0.051^{1 x} \\
0.450 \pm 0.037^{1 x} \\
0.290 \pm 0.048 \\
0.360 \pm 0.044^{2 x} \\
0.168 \pm 0.027\end{array}$ & $\begin{array}{l}0.825 \pm 0.120^{1 x} \\
0.621 \pm 0.127^{2 x} \\
0.452 \pm 0.066 \\
0.188 \pm 0.041 \\
0.744 \pm 0.131^{2 x} \\
0.491 \pm 0.138 \\
0.404 \pm 0.095 \\
0.276 \pm 0.089\end{array}$ & $\begin{array}{l}0.266 \pm 0.060^{1 x} \\
0.090 \pm 0.022^{1 x} \\
0.208 \pm 0.015^{1 x} \\
0.076 \pm 0.024^{2 x} \\
0.234 \pm 0.038^{1 x} \\
0.123 \pm 0.017 \\
0.256 \pm 0.049^{2 x} \\
0.101 \pm 0.028^{2 x}\end{array}$ \\
\hline
\end{tabular}

Indices 1 and 2 show values which differ with statistical significance (at $p_{1}$ correspondingly, $<0.05$ and $<0.01$ ) from the nearest (from the left) value of the same line (index $x$ ) or from the corresponding value referring to macrophages from rats of the same group during incubation of cells without quartz (index + ).

irregular shape consisting almost entirely of dust containing cells and with no evident fibrosis, whereas the total number of granuloma was considerably less than in the group not receiving glutamate in the lungs and particularly in the tracheobronchial

Table 4 Infuence of glutamate in vivo and quartz dust in vitro on the critical oxygen concentration $(\mu A)$ limiting the respiration of peritoneal macrophages of rats

\begin{tabular}{lll}
\hline Macrophages & \multicolumn{2}{l}{ Duration of experiment } \\
\cline { 2 - 3 } & 2 months & 4 months \\
\hline $\begin{array}{l}\text { From control rats; } \\
\text { incubation without quartz }\end{array}$ & $117.55 \pm 17.89$ & $304.08 \pm 25 \cdot 55$ \\
$\begin{array}{l}\text { From control rats; } \\
\text { incubation with quartz }\end{array}$ & $258 \cdot 16 \pm 38 \cdot 15 \dagger$ & $393.35 \pm 16.38^{*}$ \\
$\begin{array}{l}\text { From rats receiving } \\
\text { glutamate; incubation } \\
\text { without quartz }\end{array}$ & $104.36 \pm 7 \cdot 47$ & $335.43 \pm 35 \cdot 71$ \\
$\begin{array}{l}\text { From rats receiving } \\
\text { glutamate; incubation with }\end{array}$ & $206 \cdot 53 \pm 36.83^{*}$ & $369.82 \pm 25.27$ \\
\hline \begin{tabular}{l} 
quartz \\
\hline
\end{tabular}
\end{tabular}

* The value differs from the corresponding value of the line above at $p<0.01$.

tThe same at $\mathrm{p}<0.01$. lymph nodes. Peribronchial sclerosis was also less pronounced.

The main data concerning the cytological characteristics of the bronchopulmonary lavage of the rats of these two groups, as well as corresponding control groups, are given in table 1 . The quantitative indices characterising the changes of the weight of the lungs and lymph nodes, their dust content, and hydroxyproline and lipids contents are shown in table 2.

The results of the determination of the rate of

Table 5 Inftuence of preincubation with glutamate or succinate on the resistance of peritoneal macophages to the quartz dust cytotoxicity in vitro

\begin{tabular}{ll}
\hline $\begin{array}{l}\text { Preincubation } \\
\text { with }\end{array}$ & $\begin{array}{l}\text { TTC-reductase activity Statistical significance } \\
\text { of peritoneal macro- of the difference from } \\
\text { phages with } D Q_{12} \text { in the series preincubated } \\
\text { per cent of the activity without any substrate } \\
\text { of control cells }\end{array}$
\end{tabular}

Sodium glutamate

\begin{tabular}{lll} 
Sodium glutamate & \\
$3 \cdot 4 \cdot 10^{-4} \mathrm{M}$ & $70.4 \pm 7.5$ & $\mathrm{p}<0.05$ \\
Sodium succinate & & $\mathrm{NS}$ \\
$3 \cdot 4 \cdot 10^{-4} \mathrm{M}$ & $53.9 \pm 4.2$ & - \\
No substrate & $42.5 \pm 6.3$ & - \\
\hline NS $=$ Not significant.
\end{tabular}

NS $=$ Not significant 
oxygen consumption by the cells under the conditions described above are summarised in table 3; the values of critical oxygen concentration are shown in table 4 and data on the comparative antisilica cytoprotective effect of glutamate and succinate in vitro in table 5 .

\section{Discussion}

In our previous studies an increase in the resistance of peritoneal macrophages to the cytotoxic action of quartz was always observed under strictly controlled condition in vitro, regardless of whether the effect was also noted after the preincubation of the cells with glutamic acid, or after prolonged consumption of glutamate by the rats from which the cells were obtained. $^{2-4}$ We therefore had good grounds to expect that the peroral administration of glutamate would exercise a defensive action also on the resistance of pulmonary macrophages to the cytotoxic action of quartz particles deposited in the airways during inhalation. An increase in the resistance of free alveolar macrophages must, in turn, lead to an increase in the efficiency of pulmonary clearance and thereby to the decrease of the retention of dust in the lungs and, particularly, to a decrease of the penetration of dust into the lymphatic system. For those particles which are, nevertheless, retained in the lungs and lymph nodes, the increase in the resistance of tissue macrophages must lead, by the inhibition of the formation of the "fibrogenic" factor ${ }^{8-10}$ and by other mechanisms involving the intraction of macrophages and fibroblasts, ${ }^{10-13}$ to a weakening of fibrogenic activity. The results of the long term inhalation experiment have confirmed all these expectations.

As seen from table 1, in both stages of the experiment the percentage of clearly degenerated alveolar macrophage (AM) was significantly reduced by the administration of glutamate not only in the rats exposed to quartz dust (about $2 \cdot 6$ times by the third and 4.4 times by the sixth month of the experiment) but also in the rats not exposed to dust (about 1.5 times in both stages). Dust particles from city air are deposited in the airways and, although the number of such particles is lower, the recruitment of AM into the respiratory tract is also low so that the dust load on an average AM is comparable with that in the exposure chamber, especially in the first stage of the experiment. City dust, however, is considerably less cytotoxic than the quartz dust. The percentage of degenerated AM in rats inhaling quartz dust but not receiving glutamate was 2.5 times higher than in the control group in three months and 2.6 times in six months. The fact that the defensive action of glutamate in vivo is more pronounced in the case of quartz dust than in the case of city dust agrees with the previous increase in the relative defensive effect obtained in vitro with an increase in the damaging factor achieved by an increase in the dose of quartz. ${ }^{2}$ The enhanced recruitment of neutrophil leucocytes (NL) into the airways is an additional important criterion of the cytotoxicity of inhaled dust. ${ }^{14-19}$ The experience of our laboratory shows that the most informative index in this respect is the ratio of NL to AM numbers in the bronchopulmonary lavage..$^{15} 1720$ It was shown that the lower the quantity of macrophage breakdown products (MBP) in the respiratory tract, the lower the NLAM ratio. Moreover, a small reduction of the MBP dose only decreases the number of NL, whereas a greater one also decreases the number of AM. ${ }^{17}$ If, from our experiment, we take the percentage of degenerated AM as a relative measure of the MBP formed in the lower respiratory tract, it can be seen that the above relationships are confirmed by the action of glutamate. In fact, the decrease of the NLAM ratio caused by glutamate is always due to a decrease in the percentage of AM, but only when the latter are most decreased-namely, in rats inhaling quartz dust for six months - was a decrease in the absolute numbers of both NL and AM observed. All other cases (with less pronounced defensive effect of glutamate) showed a decrease only in the number of NL.

It was shown earlier that the percentage of degenerated $\mathrm{AM}$ in rats inhaling quartz produces a higher NL AM ratio than in rats not exposed to quartz. Some mechanisms to account for this difference were also studied. ${ }^{17}$ In this connection it is interesting to note that, although the average percentage of degenerated AM in rats exposed to quartz was lowered to the level of rats not exposed to quartz inhalation by the action of glutamate, the mean value of the NUAM ratio was significantly higher in the former group than in the latter. Thus an important feature of the cytotoxic action of quartz on AM was observed despite a considerable increase in the resistance of these cells to such an action.

Another piece of indirect evidence of the fact that, even with the application of glutamate, quartz remains specifically cytotoxic to the AM may be the absence of a large number of dust particles inside a single macrophage-especially by comparison with analogous data from our laboratory referring to the inhalation of less cytotoxic dust, titanium dioxide. ${ }^{17}$ The most probable cause of this may be that cells with a very large dust load cannot be found in the lavage as they die and decompose. The complete absence of a significant influence of glutamate on this index may, however, be misleading. The point is that at the time of study of the bronchopulmonary 
lavage (18-20 hours after the end of the last dust exposure) the lower respiratory tract of rats receiving glutamate was freed from deposited particles due, largely, to the higher functional stability of the cells responsible for their elimination. In other words, at that time the probability of AM encountering and engulfing a dust particle was already lower in these rats than in those who had not received glutamate. Therefore, it may be surmised that during each dust exposure and during the first hours after it, when this probability was still virtually the same in both groups, the average AM in rats receiving glutamate could tolerate a larger number of quartz particles than the AM in rats not receiving glutamate.

Data given in table 1 on the total number of phagocytised particles in AM and NL washed out of the lungs also show that at the moment of lavage this quantity is lower in the rats inhaling quartz and drinking glutamate compared with those exposed to quartz but not glutamate. The fact that we deal here with results of a more effective previous clearance, and not with the inhibition of phagocytosis, is shown by the following data on decrease of retention of quartz in the lung.

An indirect proof of the validity of the foregoing interpretation of the indices of phagocytis activity of the free respiratory tract cells with respect to inhaled dust particles (an interpretation that is valid only for the case of "peak" dust exposures, in relation to which the time of study is considerably delayed) is the fact that in the rats inhaling only dust from the city air glutamate did not cause the same decrease in the total number of phagocytised particles. On the contrary, in both stages of the experiment the total number was somewhat higher than without glutamate, whereas the contribution of neutrophile phagocytosis was lowered, reflecting the increase stability of the macrophages. At the same time the percentage of AM and NL with visible engulfed particles was not decreased as in the rats exposed to quartz dust, but was somewhat increased which, possibly, reflects a general non-specific stimulation of their functional state and may be one more cause of a more effective pulmonary clearance.

One of the important features of the adaptation of the phagocytosic mechanism of lung clearance to the changes in the cytotoxicity of dust or resistance of the macrophage is the minimum expenditure of cell resources on the effective clearance. ${ }^{17}$ In this case such adaptation was fully evidenced: despite reduced recruitment of $A M$ and especially NL, the quantity of dust deposited in lungs, and especially in the tracheobronchial lymph nodes of the rats during the inhalation periods, was considerably reduced by glutamate (table 2). If these differences are the direct result of enhanced clearance the additional reduction of dust accumulation in the lymph nodes may be explained by a decrease in the probability of lymphatic transport of the particles due to their prolonged existence in a phagocytised state as a result of increased resistance of the coniophage to dust cytotoxicity. ${ }^{21} 22$

The inhibition of the silicotic effect of quartz by glutamate was evident in the histological description of the lung granulomas after six months of the experiment. Quantitative shifts in the mass of the lungs and their hydroxyproline and lipid content due to exposure to silica were insignificant after three months exposure and, naturally, any effect of glutamate was scarcely noticeable against this background. After three months, however, a tendency to a less intensive development of silicotic changes could be observed in the rats receiving glutamate, although this tendency was not significant.

By the end of six months, the influence of glutamate of the lungs and the tracheobronchial lymph nodes of the rats not exposed to quartz is evident (a statistically significant reduction in the mass of the lungs and their hydroxyproline content being observed). If we take into consideration that during both stages of the experiment glutamate produced no influence on the mass of the other internal organs of the rats it seems likely that in the case of the lungs there has been a diminution in the chronic fibroproductive inflammation which is always observed in laboratory rats and which progresses with age, possibly due to the action of atmospheric pollutants. The correspondence between the reduction of dust retention in lungs of these rats and the reduction of the lung mass and hydroxyproline content cannot be considered coincidental.

This is even more true with respect to the rats exposed to quartz. In these animals glutamate produced an undoubtable inhibition to the silicotic action of quartz at the end of six months by all the criteria used. In fact, the hydroxyproline content of the lungs was the same as in the rats of the intact control group. A comparison of the rats exposed to quartz and receiving glutamate with those receiving glutamate but with no dust exposure shows that the fibrogenic effect of quartz dust deposited in lungs remains, although it is far less pronounced compared with the corresponding groups not receiving glutamate. The fact that the fibrogenicity of the silica is considerably reduced but at the same time persists on the background of glutamate action corresponds to a sharp but not complete inhibition of the cytotoxicity of the silica. The fact that, in the presence of quartz dust retained in the lungs the fibrosis observed is not greater than that seen in unexposed rats without glutamate treatment sup- 
ports the suggestion that glutamate reduces the fibrogenic action of quartz particles which are retained in the lungs despite stimulated pulmonary clearance. The protective effect is considerably higher than that of poly (2-vinyl-pyridine $\mathrm{N}$-oxide) judging from previous experiments conducted in our laboratory. ${ }^{23}$

When considering the data on the influence of glutamate on the oxygen consumption of the peritoneal macrophages (table 5) it should be noted that the level of endogenous respiration of the cells not incubated with quartz was the same in the rats given glutamate as in the control group. Macrophages from rats receiving glutamate for four months, however, responded to the addition of succinate by a somewhat smaller increase in the rate of respiration. This is, possibly, connected with stabilisation of the cell membrane which leads to the reduction in its permeability for the exogenous substrate. There are data ${ }^{24}$ which show that the permeability of the membrane to succinate is dependent on the degree of cell damage. When incubation with quartz caused most cell damage, judging from the decrease in the rate of endogenous respiration (about 2.2 times that of the control)-namely, in the second stage experiment with macrophages from rats not receiving glutamates - the addition of exogenous succinate gave the greatest increase in oxygen consumption (about 2.9 times). When the cell damage was less pronounced even without glutamate this increase was only 1.6-1.7 times; and at the same stage of experiment with rats receiving glutamate the increase was only 1.3 times.

Cells responding to the addition of succinate by an inhibition of respiration were discovered only in the experiment which studied the influence of quartz on macrophages from rats not receiving glutamate. Most probably, this inhibition is connected with a low energy shift of metabolism caused by cell damage. This shift is characterised by the accumulation of oxaloacetic acid (OAA) leading to the inhibition of succinate dehydrogenase..$^{25}$ The involvement of OAA in the transamination of glutamic acid ${ }^{25}$ may explain why this paradoxical reaction on succinate was not observed in the macrophages of rats receiving glutamate.

In both stages of the experiment the rate of endogenous respiration was lowered when macrophages were damaged by quartz, but in the cells from the rats receiving glutamate this decrease was less pronounced.

2, 4-Dinitrophenol, in concentrations causing an almost complete uncoupling of oxidative phosphorilation, produced an expected increase of oxygen consumption (about 1.7-2.0 times) in undamaged macrophages. In macrophages damaged by quartz this increase was, as a rule, less pronounced, reflecting the impairment of coordination of respiration and phosphorylation. Only in macrophages from rats receiving glutamate for four months was the same stimulating action of 2, 4-dinitrophenol on oxygen consumption noted both with and without incubation with quartz (1.65 and 1.69 times respectively). After incubation with quartz, some of the macrophage cultures from control rats reacted to the same concentration of 2, 4-dinitrophenol not with an increase but a decrease of respiration. This may be considered as further evidence of quartz induced damage to the macrophage mitochondria. No such inhibition was observed in experiments with macrophages from rats receiving glutamate.

Judging by changes in the rate of respiration after the addition of cyanide, the influence of quartz increased the relative contribution of cyanide resistant respiration while scarcely influencing its absolute value. In other words, the disturbances in the oxidative processes of the cell caused by quartz are almost entirely due to damage of the mitochondria; microsomal oxidation is not affected. It should be noted that during both stages of the experiment, the absolute value of cyanide resistant respiration of the macrophages, with and hout quartz induced damage, is somewhat higher than in the macrophages of control rats. This is probably due to an increased content in the cells of such NAD-dependent substrates as glutamate. Despite this, the relative contribution of cyanide resistant respiration of the macrophages of rats receiving glutamate for four months was not increased by the action of quartz, which suggests a less pronounced disturbance of mitochondrial oxidation.

The critical oxygen concentration-that is, the concentration at which the linear dependence of oxygen consumption by cells is changed to a nonlinear relationship-increases through the action of quartz on the macrophages (see table 4). This suggests that the diffusion of oxygen to oxygen consuming enzymes is diminished. The least pronounced (and statistically non-significant) change in critical oxygen consumption caused by the action of quartz was seen in the macrophages of rats receiving glutamate for four months. In both stages of the experiment the critical concentration of oxygen after incubation with quartz is lower in the macrophages of rats receiving glutamate than in those of control rats, although these differences are not statistically significant.

The polarographic data which show the favourable influence of glutamate administration on changes in adenosine nucleotide metabolism induced by the incubation of macrophages with quartz ${ }^{24}$ confirm the considerable part played by the 
normalising influence of glutamate on the energy metabolism of the cell as a mechanism for increasing its resistance to the cytotoxic action of silica. In fact, as seen from table 5, glutamate is significantly more efficient than succinate in equimolar concentrations in protecting the cell from damage by quartz in vivo. Given equal energy production, these substrates differ significantly in relation to oxydative phosphorylation: oxidation of one molecule of glutamate is accompanied by the formation of three ATP molecules, whereas two only are formed per one molecule of succinate. Thus the protective effect of glutamate is not simply due to its role as a substrate for additional energy production but may be connected with its favourable influence on the phosphorylation of ADP to ATP. There are, however, some doubts as to whether the antiquartz effect of glutamate can be fully explained by this mechanism. As we have already emphasised, ${ }^{2}$ glutamate plays a key part in many important metabolism processes, and it may be that all the important functions of glutamic acid and its amine have some relation to the increase in the resistance of cells, in particular macrophages, to the action of cytotoxic materials.

There is no reason to suppose that the defensive effect of glutamate is specifically an antiquartz effect. It also counteracts the damage to mitochondrial oxidative phosphorylation seen in acute carbon tetrachloride poisoning. ${ }^{27}$ The antitoxic effect of glutamate has also been shown in experimental poisoning with sodium fluoride. ${ }^{28}$ We have shown that the manifestations of the defensive action of glutamate in vivo are observed to some extent also in relation to non-specific chronic lung pathology in laboratory rats. It would be difficult, however, to find a pathological process other than silicosis in which specific primary damage to a particular cell type plays such an important part in its production; the damaging of pulmonary macrophages by silica particles affects the kinetics of the retention and translocation of silica particles and induces the development of tissue fibrosis and leads to immunopathological elements of the disease. Therefore, even in view of the non-specificity of the defensive action of glutamate on the pulmonary macrophage, it may be considered an effective means of preventing the disease.

\section{References}

' Aronova GV, Velichkovski BT, Genkin AM, Elnichnykh LN, Morosova KI. Antifibrotic effect of glutamic acid in experimental silicosis and asbestosis. Gig Tr Prog Zabol 1980; 1:12-5*

${ }^{2}$ Morozova KI, Aronova GV, Katsnelson BA, et al. On the defensive action of glutamate against the cytotoxicity and fibrogenicity of quartz dust. $\mathrm{Br} J$ Ind $\mathrm{Med}$ 1982;39:244-52.
${ }^{3}$ Morosova KI. Influence of glutamatic acid on the macrophage resistance to the cytotoxic action of quartz. In: Domnin SG, Katsnelson BA, eds. Occupational diseases of dust aetiology. Moscow: Erisman Institute of Hygiene, 1980:74-8.*

${ }^{4}$ Morosova KI. On the mechanism of antisilicotic action of glutamic acid. Gig Tr Prof Zabol 1980;8:36-8.*

stacy BD, King EJ. Silica and collagen in the lungs of silicotic rats treated with cortisone. Br J Ind Med 1954;11:192-8.

- Chvapil M. Möglichkeiten einer quantitativen Bestimmung des Fibrosegrades bei der Untersuchung experimentellar Silikose. Beiträge zur Silikose-Forschung 1960;64:3-71.

' Katsnelson BA, Babushkina LG, Velichkovski BT. Changes of total lipid content in lungs of rats in experimental silicotical lipid content in lungs of rats in experimental silicosis. Byulleten Experimentalnoj Biologii $i$ Meditsiny 1964;6:49-54.*

${ }^{8}$ Heppleston AG. The fibrogenic action of silica. Br Med Bull 1969;25:282-7.

' Burell R, Anderson M. The induction of fibrogenesis by silicatreated alveolar macrophages. Environ Res 1973;6:389-94.

${ }^{10}$ Nourse LD, Nourse PN, Botes H, Schwartz HM. The effect of macrophages isolated from lungs of guinea-pigs dusted with silica on collagen biosynthesis by guinea pig fibroblasts in cell culture. Environ Res 1975;9:115-27.

"Allison AC, Clark JA, Davies P. Cellular interaction in fibrogenesis. Ann Rheum Dis 1977;36 suppl:8-11.

12 Aho S, Feltonen J, Jalkanen M, Kulonen E. Effect of silica on a culture of rat peritoneal macrophages. Ann Occup Hyg 1979; 22:285-96.

${ }^{13}$ Aho S, Kulonen E. Involvement of ribonuclease in the interaction of macrophages and fibroblasts in experimental silicosis. Experientia 1980;36:29-31.

14 Starikova SK. The importance of different phagocytic cells for self-clearance of lungs from quartz dust. Byulleten Experimentalnoj Biologii $i$ Meditsiny 1969;68:27-9.*

is Starikova SK, Katsnelson BA. On the influence of some factors on the pattern and efficiency of the alveolar phagocytosis of quartz dust. Gig Tr Prof Zabol 1970;10:48-50.*

${ }^{16}$ Starikova SK, Katsnelson BA, Aronova GV, Schnaidman IM. The contribution of polynuclears to the alveolar phagocytosis of quartz dust and its connection with the biological aggressivity of quartz. Byulleten Experimentalnoj Biologii $i$ Meditsiny 1970; 76:113-6.*

${ }^{17}$ Privalova LI, Katsnelson BA, Osipenko AB, Yushkov BN, Babushkina LG. Response of a phagocytic cell system to products of macrophage breakdown as a probable mechanism of alveolar phagocytosis adaptation to deposition of particles of different cytotoxicity. Environ Health Perspect 1980; 35: 205-18.

${ }^{18}$ Morgan A, Moores SR, Holmes A, Evans SC, Evans NH, Black A. The effect of quartz, administered by intratracheal instillation, on the rat lung. 1. The cellular response. Environ Res 1980;22:1-12.

19 Beck BD, Brain JD, Bohannon DE. The pulmonary toxicity of an ash sample from the Mt St Helens volcano. Exp Lung Res 1981;2:289-301.

${ }^{20}$ Podgaiko GA, Katsnelson BA, Lemyasev MF, Solomina SH, Saitov VA, Rusyaeva LV. New data on silicosis hazard of aerosols on base of colloidal silicic acid solution. In: Domnin SG, Katsnelson BA, eds. Occupational diseases of dust aetiology. Moscow: Erisman Institute of Hygiene, 1982:68-78.*

${ }^{21}$ Katsnelson BA, Babushkina LG. On the significance of dust retention in lymph nodes and of increase of their weight for the experimental evaluation of pneumoconiosis hazard of different dusts. Gig Sanit 1968;3:108-10.*

${ }^{22}$ Gross P, De Treville TP. The lung as embattled domain against inanimate pollutants. A precis of mechanisms. Am Rev Respir Dis 1972;106:684-92.

${ }^{23}$ Katsnelson BA, Babushkina LG, Aronova GV, et al. On antisilicotic action of polyvinylpyridine- $\mathrm{N}$-oxide in experiment. Gig Sanit 1970;10:20-84.* 
24 Jally WW, Wilhelm DD, Harris RA. Assesment of tissue and cell damage by succinate oxidation. J Mol Cell Cardiol 1979;11:485-500.

${ }^{25}$ Kondrashova MN. Fundamental concepts of bioenergetics as used in physiological investigations. In: Regulation of energy metabolism and stability of organism. Pushchino: USSR Academy of Sciences, 1975:67-82.*

26 Volkov MS, Genkin AM, Glotov NA, Mayevski EI. Glutamic acid. Biochemical foundation of practical use. Sverdlovsk:
Sredne-Uralskoye Kniznoye Izdatelstvo, 1975:119.*

${ }^{27}$ Serbinovskaya NA, Rotenberg YS. Use of succinate and glutamate in the carbon tetrachloride poisoning. In: Therapeutic effects of succinate. Pushchino: USSR Academy of Sciences, 1976:179-80.

2s Shugayev VA. Effect of glutamic acid on sodium fluoride toxicity. Farmakol Toksikol 1973;4:449-51.*

*In Russian. 